\title{
The interactive effects of microcystin-LR and cylindrospermopsin on the growth rate of the freshwater algae Chlorella vulgaris
}

\author{
Carlos Pinheiro $^{1,2} \cdot$ Joana Azevedo $^{2,3} \cdot$ Alexandre Campos $^{2} \cdot$ Vítor Vasconcelos $^{2,4}$ • \\ Susana Loureiro ${ }^{1}$ \\ Departamento de Biologia \& CESAM, Universidade de Aveiro, 3810-193 Aveiro, Portugal \\ Centro Interdisciplinar de Investigac, a o Marinha e Ambiental, CIIMAR/CIMAR, Rua dos Bragas 289, 4050-123 Porto, \\ Portugal \\ 3 Escola Superior de Tecnologia da Saúde do Porto, Rua Valente Perfeito, 322, 440-330 Vila Nova de Gaia, Portugal \\ 4 Departamento de Biologia, Faculdade de Cie^ncias da Universidade do Porto, Rua do Campo Alegre, 4069-007 Porto, \\ Portugal
}

\begin{abstract}
Microcystin-LR (MC-LR) and cylindrospermopsin $(\mathrm{CYN})$ are the most representative cyanobacterial cyanotoxins. They have been simultaneously detected in aquatic systems, but their combined ecotoxicological effects to aquatic organisms, especially microalgae, is unknown. In this study, we examined the effects of these cyanotoxins individually and as a binary mixture on the growth rate of the freshwater algae Chlorella vulgaris. Using the MIXTOX tool, the reference model concentration addition (CA) was selected to evaluate the combined effects of MC-LR and CYN on the growth of the freshwater green algae due to its conservative prediction of mixture effect for putative similar or dissimilar acting chemicals. Deviations from the CA model such as synergism/antagonism, dose-ratio and dose-level dependency were also assessed. In single exposures, our results demonstrated that MC-LR and CYN had different impacts on the growth rates of $C$. vulgaris at the highest tested concentrations, being CYN the most toxic. In the mixture exposure trial, MC-LR and CYN showed a synergistic deviation from the conceptual model $\mathrm{CA}$ as the best descriptive model. MC-LR individually was not toxic even at high concentrations $\left(37 \mathrm{mg} \mathrm{L}^{-1}\right)$; however, the presence of MC-LR at much lower concentrations (0.4-16.7 $\mathrm{mg} \mathrm{L}^{-1}$ ) increased the CYN toxicity. From these results, the combined exposure of MC-LR and CYN should be considered for risk assessment of mixtures as the toxicity may be underestimated when looking only at the single cyanotoxins and not their combination. This study also represents an important step to understand the interactions among MC-LR and CYN detected previously in aquatic systems.
\end{abstract}

Keywords Cyanotoxins - Microcystin-LR . Cylindrospermopsin - Chlorella vulgaris - Synergism . Concentration addition

\section{Introduction}

Cyanobacterial blooms in eutrophic water bodies have become a serious environmental problem worldwide, as many genera of bloom-forming cyanobacteria are able to produce potent cyanotoxins that are released in significantly high concentrations into the aquatic environment upon cell ruptures (Bláha et al. 2009; Wiegand and Pflugmacher 2005). These cyanotoxins include hepatotoxins, neurotoxins, cytotoxins and dermatotoxins and irritant toxins, representing a major health hazard for animals and humans (Codd et al. 1999; Falconer 1999; van Apeldoorn et al. 2007). Furthermore, there is a prediction that such cyanobacterial blooms are likely to increase in prevalence and magnitude in the future with climate changes, especially with the predicted rise of global temperatures (Paerl and Huisman 2008, 2009; Paerl and Paul 2012). With this predicted rising of cyanobacterial bloom occurrence, the 
release of high cyanotoxin concentrations could considerably become more common in the aquatic environment, and therefore instigating the evaluation of a wide range of concentrations which include extremely high concentrations.

The majority of cyanotoxin poisoning reports have been directly related to two toxin groups, microcystins (MCs) and cylindrospermopsin (CYN) (Falconer and Humpage 2005). Both cyanotoxins are produced by a larger number of cyanobacterial species around the world (Wiegand and Pflugmacher 2005). MCs are the most common and ubiquitous cyanotoxins in brackish and freshwater blooms (Zurawell et al. 2005) and to date more than $80 \mathrm{MC}$ variants have been isolated and identified, being MC-LR the most common and toxic variant (Dittmann and Wiegand 2006). They are stable cyclic heptapeptides (Tsuji et al. 1994; van Apeldoorn et al. 2007), whose mechanism of toxicity is mainly based on the induction of oxidative stress (Amado and Monserrat 2010) and inhibition of protein phosphatases 1 and 2A in aquatic animals and higher plants (Gulledge et al. 2002; Mackintosh et al. 1990; Runnegar et al. 1995a). It has been suggested that abnormal organization of microtubules (including the disruption of mitotic spindles and phragmoplasts and the formation of monopolar/multipolar spindles) and hyperphosphorylation of histone $\mathrm{H} 3$ (resulting in incomplete chromatid segregation and formation of micronuclei) are the two main mechanisms of toxicity of MCs on plants (Máthé et al. 2013). These processes can be correlated directly to the protein phosphatases inhibitory effect induced by MCs. CYN is a widespread (Falconer and Humpage 2006; Fastner et al. 2007; Quesada et al. 2006; Spoof et al. 2006) and stable (Chiswell et al. 1999; Wormer et al. 2008) tricyclic alkaloid. Only two CYN variants have been reported: 7-epiCYN, with similar toxicity to CYN (Banker et al. 2000), and 7-deoxyCYN, whose toxicity is well recognized by some authors (Neumann et al. 2007), but was questioned by others (Norris et al. 1999, 2002). It is established that CYN may act through the glutathione and protein synthesis inhibition in mammals (Froscio et al. 2001, 2008; Runnegar et al. 1995b; Terao et al. 1994), a process likely mediated by cytochrome P450 (CYP450)-generated metabolites (Humpage et al. 2005). The few studies that have analyzed the effects of CYN on plants indicate that it results in the alteration of microtubule formation (including preprophase bands) and disruption of spindle-phragmoplast directly related to protein synthesis inhibition (Máthé et al. 2013; Metcalf et al. 2004).

Individual blooms may contain multiple cyanobacterial species in the same water body and many cyanobacterial strains may produce more than one type of cyanotoxin as well as different congeners of the same type of cyanotoxin (e.g. MC congeners). Some studies have reported the concurrent presence of MC-LR and CYN in water (Bogialli et al. 2006; Brient et al. 2009; Oehrle et al. 2010) as well as the coexistence of potentially MC-LR- and CYN-producing cyanobacteria (Bláhová et al. 2009; Kokociński et al. 2009; Vasas et al. 2004). Therefore, it might be expected that when MC-LR and CYN occur simultaneously in the water, and persist for days in the region of blooms (Eaglesham et al. 1999; Lahti et al. 1997), they have serious combined impacts on aquatic organisms, including microalgae. Although the single toxic effects of MC-LR and CYN on aquatic organisms have been widely investigated as pure cyanotoxins (Babica et al. 2006, 2007; Beyer et al. 2009; Lindsay et al. 2006) and/or MC-LR- and CYNcontaining crude extracts (Pflugmacher et al. 1999; Prieto et al. 2011), information available on their combined effects is still scarce. Given the co-occurrence, stability and persistence of MC-LR and CYN, it is important to assess the extent to which synergism is a concern.

The aim of this study was thus to examine the effects of MC-LR and CYN, independently and in combination, on the growth of the freshwater Chlorella vulgaris. Two noninteraction conceptual models are commonly used to predict the toxicity of chemical mixtures: concentration addition (CA) and independent action (IA) (Jonker et al. 2005). The concept of CA assumes that chemicals share the same modes of action (MoA) for toxicity. The concept of IA assumes that the chemicals elicit their effects through different MoA and do not interfere with each other during exposure, uptake and toxic action (Olmstead and LeBlanc 2005). To predict the combined effects of both cyanotoxins on $C$. vulgaris, the model of CA was used in this study instead of IA model because it has been considered more conservative in the prediction of mixture toxicity and may be defendable as a precautionary default assumption (European Food Safety Authority 2015). However, deviations from the CA model may occur and therefore a different behavior may be expected. These deviations are those where a given mixture causes a more severe (synergism) or less severe (antagonism) effect than the predicted by the CA model. These deviations can be constant throughout the concentrations used or vary and follow a dose-level dependency (i.e. different effects at high and low concentrations) and a dose-ratio dependency (i.e. effects differ depending on the mixture composition) (Jonker et al. 2005).

Specifically, we tested the following hypothesis: (1) dissolved CYN and MC-LR will induce no harm on the growth response of the freshwater microalgae and (2) there will be an additivity of effects between these two cyanotoxins regarding the $\mathrm{CA}$ model. We tested these hypotheses by determining the growth rate of the freshwater microalgae $C$. vulgaris after 4 and 7 days of exposure over a range of high pure toxin levels. Although the 
concentrations used are not ecologically relevant, this approach will enable the understanding of cyanotoxins toxicity under mixtures, and can therefore be transposed using safety factors to convert the non-ecologically relevant pure toxin levels in more ecologically relevant levels.

\section{Materials and methods}

\section{Test organism, cyanobacterial strains and culture conditions}

C. vulgaris (LEGE Z-001) from Algoteca, University of Coimbra-ACOI-879 was maintained as axenic culture in the laboratory. C. vulgaris is normally used for algal toxicity tests and being from freshwater environments may co-occur with MC-LR- and CYN-producing cyanobacteria. Therefore, it is a relevant species to provide further insights on the effects of cyanotoxin mixtures in freshwater phytoplankton. Microcystis aeruginosa (LEGE 91094) was isolated from Lagoa de Mira, Portugal and Aphanizomenon ovalisporum (LEGE X-001) from Lake Kinnerett, Israel. Species identification was confirmed in the laboratory by morphology. The strain $M$. aeruginosa was reported to produce mainly the MC-LR variant, accounting for approximately $95 \%$ of the total intracellular MCs (Pereira et al. 2009). The strain A. ovalisporum was verified by a Water Alliance e2695 HPLC system (Milford, Massachusetts, USA) coupled with a PDA 2998 to produce only CYN (data not shown).

All species were grown in Z8 medium (Kotai 1972), at $25 \pm 2{ }^{\circ} \mathrm{C}$ under a light intensity of $10 \mu \mathrm{mol} \mathrm{m} \mathrm{m}^{-2} \mathrm{~s}^{-1}$ photon irradiance with a photoperiod of $14 \mathrm{~h}$ light and $10 \mathrm{~h}$ dark. Cultures were aerated with ambient air filtered through $0.22 \mu \mathrm{m}$. After 3-4 weeks of culturing, cyanobacterial biomasses were collected by centrifugation (M. aeruginosa) or filtration (A. ovalisporum) and thereafter frozen at $-80{ }^{\circ} \mathrm{C}$ and lyophilized (Pinheiro et al. 2013). C. vulgaris cultures were renewed after 7-8 days of growth (exponential phase) with $5 \times 10^{5}$ cell $\mathrm{mL}^{-1}$ cell density. Absence of bacterial contamination was confirmed by optical microscopy (Pinheiro et al. 2013).

\section{Extraction, purification and quantification of MC- LR and CYN}

MC-LR was extracted according to the method described by Pinheiro et al. (2013). Briefly, the lyophilized $M$. aeruginosa biomass was extracted with $\mathrm{MeOH} 75 \%(\mathrm{v} / \mathrm{v})$ through continuous stirring for $20 \mathrm{~min}$ at room temperature. The sample was then sonicated in a bath for $15 \mathrm{~min}$ at room temperature and subsequently ultrasonicated on ice at $60 \mathrm{~Hz}$ (VibraCell 50-sonics \& Material Inc. Danbury, CT,
USA), with 5 cycles of $1 \mathrm{~min}$. The homogenate was centrifuged $(10,000 \times g, 15 \mathrm{~min})$ to remove cell debris and the supernatant collected and applied to a solid-phase extraction. The toxin MC-LR was eluted using $\mathrm{MeOH} 80 \%(\mathrm{v} / \mathrm{v})$ and concentrated by rotary evaporation at $35{ }^{\circ} \mathrm{C}$ (Pinheiro et al. 2013). The MC-LR was thereafter purified and quantified by HPLC-PDA. A reversed phase column (Phenomenex Luna RP-18, $25 \mathrm{~cm} \times 10 \mathrm{~mm}, 10 \mu \mathrm{m}$ ) kept at $35{ }^{\circ} \mathrm{C}$ were used for MC-LR purification. The gradient elution used was $\mathrm{MeOH}$ and water both acidified with $0.1 \%$ trifluoracetic acid (TFA) and the flow rate $2.5 \mathrm{~mL} \mathrm{~min}^{-1}$. The injected volume was $500 \mu \mathrm{L}$. Peak purity and percentage of purified MC-LR were calculated at 214 and $238 \mathrm{~nm}$. The MC-LR fraction was then evaporated with air nitrogen and the residue resuspended in culture medium to the desired concentration. For MC-LR quantification, a reversed phase column (Meck Lichrospher RP-18 endcapped, $25 \mathrm{~cm} \times 4.6 \mathrm{~mm}, 5 \mu \mathrm{m}$ ) equipped with a guard column $(4 \times 4 \mathrm{~mm}, 5 \mu \mathrm{m})$ both kept at $45^{\circ} \mathrm{C}$ were used. The gradient elution consisted of (A) $\mathrm{MeOH}+0.1 \%$ TFA and (B) $\mathrm{H}_{2} \mathrm{O}+0.1 \%$ TFA $(55 \% \mathrm{~A}$ and $45 \% \mathrm{~B}$ at $0 \mathrm{~min}, 65 \% \mathrm{~A}$ and $35 \% \mathrm{~B}$ at $5 \mathrm{~min}, 80 \% \mathrm{~A}$ and $20 \% \mathrm{~B}$ at $10 \mathrm{~min}, 100 \% \mathrm{~A}$ at $15 \mathrm{~min}$, $55 \% \mathrm{~A}$ and $45 \% \mathrm{~B}$ at 15.1 and $20 \mathrm{~min}$ ) with a flow rate of $0.9 \mathrm{~mL} \min ^{-1}$. The injected volume was $20 \mu \mathrm{L}$. The PDA range was $210-440 \mathrm{~nm}$, with a fixed wavelength at $238 \mathrm{~nm}$. The MC-LR was identified by comparison of spectra and retention time with a standard of MC-LR ( $\geq 95 \%$ purity, Sigma-Aldrich). The system was calibrated using a set of seven dilutions of MC-LR standard $\left(0.5-20 \mu \mathrm{g} \mathrm{mL}^{-1}\right)$ in $\mathrm{MeOH} 50 \%$. The limit of detection of the MC-LR in the HPLC-PDA system is $0.2 \mu \mathrm{g} \mathrm{mL}{ }^{-1}$.

CYN was extracted according to the method described by Pinheiro et al. (2013). Briefly, the lyophilized A. ovaliporum biomass was extracted with distilled $\mathrm{H}_{2}$ $\mathrm{O}+\mathrm{TFA} 0.1 \%(\mathrm{v} / \mathrm{v})$ by continuous stirring for $1 \mathrm{~h}$ at room temperature. The sample was then sonicated in a bath for $15 \mathrm{~min}$ and subsequently ultrasonicated on ice at $60 \mathrm{~Hz}$, with 5 cycles of $1 \mathrm{~min}$. After the extraction step, the homogenate was centrifuged $(20,000 \times g, 20 \mathrm{~min})$ and the supernatant collected and store at $-20^{\circ} \mathrm{C}$. CYN was thereafter purified by the same HPLC system using a Gemini $\mathrm{C}_{18}$ column $(250 \times 10 \mathrm{~mm}, 5 \mu \mathrm{m})$ from Phenomenex (Torrance, California, USA), kept at $40{ }^{\circ} \mathrm{C}$. The isocratic elution utilized $\mathrm{MeOH} 5 \%$ (v/v) containing $2 \mathrm{mM}$ of sodium 1-heptanesulfonate monohydrate, with a flow rate of $3 \mathrm{~mL} \mathrm{~min}{ }^{-1}$. The injection volume was $500 \mu \mathrm{L}$. Peak purity and percentage of purified CYN was calculated at $262 \mathrm{~nm}$. The CYN fraction was then evaporated by speed-vac at $30{ }^{\circ} \mathrm{C}$ and the residue resuspended in culture medium to the desired concentration. For CYN quantification, it was used an Atlantis ${ }^{\circledR}$ HILLIC phase column $(250 \times 10 \mathrm{~mm}, 5 \mu \mathrm{m})$ from Waters kept at $40{ }^{\circ} \mathrm{C}$ 
and the same isocratic elution, with a flow rate of $0.9 \mathrm{~mL} \mathrm{~min}^{-1}$ and a injected volume of $10 \mu \mathrm{L}$. The PDA range was 210-400 nm with a fixed wavelength of $262 \mathrm{~nm}$. The CYN was identified by comparison of spectra and retention time with a standard of CYN (100\% purity, Cork University, Ireland). The system was calibrated using a set of seven dilutions of CYN standard $\left(0.5-20 \mu \mathrm{g} \mathrm{mL}^{-1}\right)$ in ultrapure water. The limit of detection of the CYN in the HPLC-PDA system is $0.3 \mu \mathrm{g} \mathrm{mL}^{-1}$.

After analysis, the final concentration of MC-LR and CYN stock solution were 308.5 and $325.1 \mathrm{mg} \mathrm{L}^{-1}$ and its chromatographic purity were 97 and $98 \%$, respectively. Both cyanotoxins were then diluted in culture medium to the concentration range used in experiments.

\section{Experimental design}

An experimental design which includes simultaneously single exposures of each cyanotoxin and a set of 25 binary combinations was chosen for the mixture testing. A ray design was chosen to assess the mixture of MC-LR and CYN (Fig. 1).

Nominal concentrations of MC-LR used in single exposures were $1,5,10,20$ and $40 \mathrm{mg} \mathrm{L}^{-1}$ and in combined exposures were $0.5,2.5,5,10$ and $20 \mathrm{mg} \mathrm{L}^{-1}$. For CYN nominal concentrations were 10, 20, 40 and $80 \mathrm{mg} \mathrm{L}^{-1}$ in single exposures and $0.5,2.5,5,10$ and $20 \mathrm{mg} \mathrm{L}^{-1}$ in combined exposures. High concentrations were selected for single exposures because the toxicity prediction of binary mixture exposures is based on full concentration-response curves and in a previous work effects from lower concentrations did not reach $50 \%$ inhibition in the $C$. vulgaris growth rates (Pinheiro et al. 2013). Each concentration in single and combined experiments was tested in three replicates. In addition, a negative control was also tested in triplicate. The single and mixture exposures were carried out at the same time so that

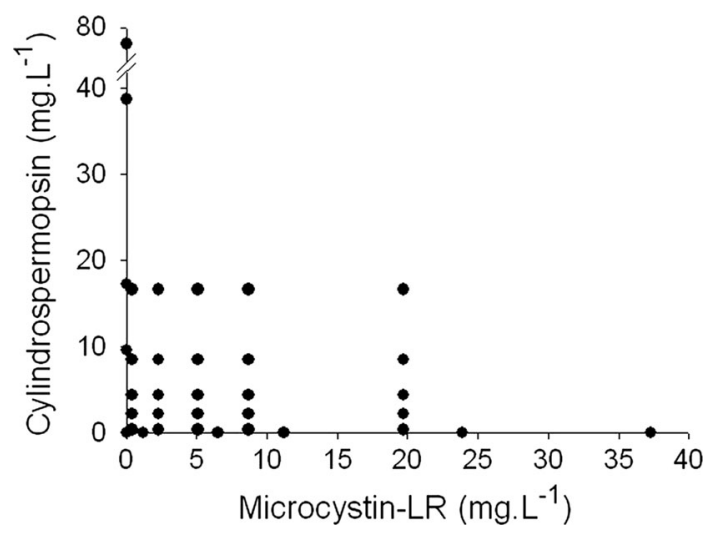

Fig. 1 A schematic ray design of the combination used for the microcystin-LR and cylindrospermopsin mixture differences in organisms responses, due to the sensitivity variations, could be controlled and not invalidate the analysis. Validity of the experiment was controlled using the reference substance potassium dichromate in three concentrations $\left(5,10\right.$ and $\left.20 \mathrm{mg} \mathrm{L}^{-1}\right)$ with 5 replicates each.

All the samples of the MC-LR- and CYN-containing exposure medium were quantified by HPLC-PDA as described above. The stability of MC-LR and CYN was also monitored during the exposure period by HPLC-PDA using samples with the same concentrations in the same conditions used for the experiment.

\section{Growth inhibition test with $C$. vulgaris}

The growth inhibition test with the freshwater algae $C$. vulgaris was performed in 96-well polystyrene microplates based on the method described by Gantar et al. (2008) due to the experimental design used and the amount of cyanotoxins necessary for the concentration range selected for the experiments. Each well consisted of $200 \mu \mathrm{L}$ of test solution (with or without cyanotoxin). The log-phase growing microalgae was exposed for 7 days to each cyanotoxin singly and in mixture and the algae growth was determined in accordance with the OECD 201 Guideline (2006). Control was represented by growing $C$. vulgaris in $\mathrm{Z} 8$ medium in the absence of cyanotoxins.

Microplates were sealed with perforated parafilm (to reduce evaporation and allow gas exchanges) and incubated for 7 days under the same conditions described above for microalgal cultures. The initial cell concentration of $C$. vulgaris was of approximately $5 \times 10^{5}$ cells $\mathrm{mL}^{-1}$. At the beginning of the experiments and after 4 and 7 days of exposure the algae concentration was measured by optical density at $750 \mathrm{~nm}$ using a microplate reader (PowerWave, Biotek, Vermont, USA). Before the measurement of optical density (on day 4 and 7), the well content was resuspended with a pipette. The optical density values were then converted in cell density (using the equation: $C=3.00 \times 10^{7} A b s+2.17 \times 10^{5}, \mathrm{R}^{2}=0.99$, where $C$ is the algae concentration in cell $\mathrm{mL}^{-1}$ and $A b s$ is the absorbance obtained at $750 \mathrm{~nm}$ ) and the average specific growth rate calculated as described in Pinheiro et al. (2013). The pH values were recorded in the beginning (range 7.3-7.4) and at the end (range 9.1-9.4) of the experiments.

\section{Data analysis}

One-way ANOVA, followed by Dunnett's multiple comparisons test, was performed using the SigmaPlot software (SPSS, 2002) to determine significant differences in the growth rate of $C$. vulgaris between the control and the 
tested concentrations. Results were considered significant at $P<0.05$. The $\mathrm{EC}_{50}$ values for single exposures to cyanotoxins at 4 and 7 days were, when possible, calculated through a three-parameter logistic regression curve.

The mixture data were analyzed using the MIXTOX tool described by Jonker et al. (2005) which allowed comparing the observed combined toxic effect and the expected combined effect calculated from the single cyanotoxin exposures. When the concentration-response curve could not be obtained, the analysis in the MIXTOX tool were conducted with fixed $\mathrm{EC}_{50}$ and slope parameters according to Loureiro et al. (2010). Growth rates from exposure to MC-LR and CYN mixture were firstly fit to the CA model. In a second step of the data analysis, CA model was extended to test to the interactions between the two cyanotoxins with deviation functions describing synergism/antagonism (S/A), dose-ratio dependent deviation (DR) and dose-level dependent deviations (DL). The S/A deviations are extensions of the CA model and the DR and DL deviations are further extensions of the S/A function [see details in Jonker et al. (2005)]. These deviations are obtained with the addition of the parameters $a$ and $b$ forming a nested framework. The extra parameter $a$ in the S/A deviation model can become negative or positive for CA. If the value of parameter $a$ is positive, this means that a smaller effect than expected (antagonism) was observed; if the referred parameter $a$ is negative, thus it expresses a higher effect than expected (synergism). When the value of parameter $a$ is zero, the S/A reduces to the CA reference model. For DR dependency, a second parameter $b_{\mathrm{DR}}$ is included in addition to $a$, to generate the DR deviation model. In this deviation function, the parameter $b_{\mathrm{DR}}$ allows the deviation from CA model to depend on the composition of the mixture. If the $b_{\mathrm{DR}}$ value is positive, antagonism may be observed where the toxicity of the mixture is caused mainly by one of the toxicants; if the $b_{\mathrm{DR}}$ value is negative, synergism may be observed where the toxicity of the mixture is caused mainly by the other one. To describe deviations of DL dependency, again a second parameter $b_{\mathrm{DL}}$ is included in addition to $a$. DL describes synergism/ antagonism depending on the concentrations of each toxicant in the mixture. In this case $a$ value allows to observe whether synergism occurs at low concentrations and antagonism at high concentrations (parameter $a$ smaller than zero) or whether antagonism occurs at low concentrations and synergism at high concentrations (parameter $a$ higher than zero). The parameter $b_{\mathrm{DL}}$ indicates at what concentration level the change between the two deviations occurs (i.e. from antagonism to synergism or vice versa); e.g., at the $\mathrm{EC}_{50}$, below the $\mathrm{EC}_{50}$ or above the $\mathrm{EC}_{50}$ level. The biological interpretations of the additional parameters are described in more detail in Table 1. The CA model and their deviations were fitted to the data using the method of maximum likelihood and statistically compared through likelihood testing. The best fit was chosen at the significance level of 0.05 using the $\chi^{2}$ test which implies a decrease in the residuals of the sum of squares (SS) and an increase in the description of the variation of the data $\left(R^{2}\right)$. When a deviation from CA model was obtained, the effect pattern was deduced directly from the parameter values as described in Table 1.

In addition, synergistic ratios (SRs) were calculated in order to estimate the magnitude of the synergistic inhibition of growth rate, exerted by the chemical mixture. This was done because it was observed that the range of concentrations used for the MC-LR exposure did not inhibit growth rate, thus not allowing for a concentration-response curve to be obtained. In order to calculate SRs, the $\mathrm{EC}_{50}$ values for CYN were firstly estimated for each MC-LR concentration used in the mixture experiment using, where feasible, the same three-parameter logistic regression curve (the same concentration-response regression curve used within the MIXTOX model). SRs were then calculated as the quotient between the $\mathrm{EC}_{50}$ value for $\mathrm{CYN}$ (without MC-LR) and the $\mathrm{EC}_{50}$ values for each of the MC-LR and CYN treatments. SRs of 1.0 indicate no effects of the MCLR on CYN toxicity (or an additive response), whereas values of $>1.0$ and $<1.0$ indicate greater and less effects than expected, respectively.

\section{Results}

\section{Chemical analysis}

To assess contamination accuracy, MC-LR and CYN analyzes were made by HPLC-PDA and the results showed that some measured concentrations varied generally more than $20 \%$ from the nominal concentrations. So, all calculations were based on effective concentrations.

Stability analyzes for MC-LR and CYN were also made by HPLC-PDA and the results showed no toxin degradation throughout the 7 days of exposure. No significant changes in the $\mathrm{pH}$ were observed during the exposure period, indicating that this parameter was not interfering with $C$. vulgaris response to the cyanotoxin treatments.

\section{Single exposures}

A significant increase in C. vulgaris growth rate was registered at the highest concentrations of MC-LR (6.5-37.3 $\left.\mathrm{mg} \mathrm{L}^{-1}\right)$ after 7 days of exposure; the no observed effect concentration (NOEC) and the lowest observed effect concentration (LOEC) values of 1.2 and $6.5 \mathrm{mg} \mathrm{L}^{-1}$ were obtained for MC-LR, respectively (Fig. 2). No significant differences compared to control 
Table 1 Interpretation of additional parameters $(a$ and $b)$ that define the functional form of deviation patterns from concentration addition

\begin{tabular}{|c|c|c|}
\hline \multirow[t]{2}{*}{ Deviation pattern } & \multicolumn{2}{|l|}{ Concentration addition } \\
\hline & Parameter $a$ & Parameter $b$ \\
\hline $\begin{array}{l}\text { Synergism/ } \\
\text { antagonism (S/A) }\end{array}$ & $\begin{array}{l}\boldsymbol{a}>\mathbf{0}: \text { antagonism } \\
\boldsymbol{a}<\mathbf{0}: \text { synergism }\end{array}$ & \\
\hline $\begin{array}{l}\text { Dose ratio } \\
\text { dependent (DR) }\end{array}$ & $\begin{array}{l}\boldsymbol{a}>\mathbf{0} \text { : antagonism except for those mixture ratios where } \\
\text { negative } \mathrm{b} \text { value indicate synergism } \\
\boldsymbol{a}<\mathbf{0} \text { : synergism except for those mixture ratios where positive } \\
\text { b value indicate antagonism }\end{array}$ & $\begin{array}{l}\boldsymbol{b}_{\boldsymbol{i}}>\boldsymbol{0} \text { : antagonism where the toxicity of the mixture is } \\
\text { caused mainly by toxicant } i \\
\boldsymbol{b}_{\boldsymbol{i}}<\mathbf{0} \text { : synergism where the toxicity of the mixture is } \\
\text { caused mainly by toxicant } i\end{array}$ \\
\hline \multirow[t]{4}{*}{$\begin{array}{l}\text { Dose level } \\
\text { dependent (DL) }\end{array}$} & $\begin{array}{l}\boldsymbol{a}>\mathbf{0} \text { : antagonism low dose level and synergism high dose } \\
\text { level }\end{array}$ & $b_{D L}>1$ : change at lower $\mathrm{EC}_{50}$ level \\
\hline & & $\boldsymbol{b}_{D L}=1:$ change at $\mathrm{EC}_{50}$ level \\
\hline & $\begin{array}{l}\boldsymbol{a}<\mathbf{0} \text { : synergism low dose level and antagonism high dose } \\
\text { level }\end{array}$ & $\mathbf{0}<\boldsymbol{b}_{\boldsymbol{D L}}<\mathbf{1}$ : change at higher $\mathrm{EC}_{50}$ level \\
\hline & & $\begin{array}{l}\boldsymbol{b}_{\boldsymbol{D L}}<\mathbf{0} \text { : no change, but the magnitude of S/A is effect } \\
\text { level dependent }\end{array}$ \\
\hline
\end{tabular}

Adapted from Jonker et al. (2005)

$\mathrm{EC}_{50}$ is the median effect concentration

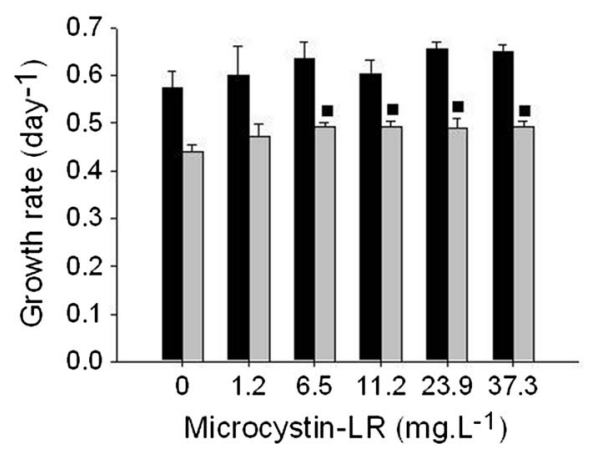

Fig. 2 Growth rate of the microalgae Chlorella vulgaris after 4 (black bars) and 7 (grey bars) days of exposure to pure MC-LR (left side) and CYN (right side) in the single exposures of the mixture experiment. Results are expressed as average \pm standard error.

were observed in C. vulgaris growth rates after 4 days of exposure to MC-LR (Fig. 2).

The growth response of $C$. vulgaris over the 4 and 7 days' exposure to CYN followed a concentration-response relationship as the growth rates decreased significantly with increasing CYN concentrations (Fig. 2). Significant differences compared to control were found at 38.7 and $76.1 \mathrm{mg} \mathrm{L}^{-1}$ for both exposure periods. At these CYN concentrations, the growth rate values were about 3.14- and 3.58-fold lower than the control after 4 days of exposure, and 2.84- and 4.15-fold lower than the control after 7 days of exposure, respectively. A significant increase in C. vulgaris growth rate was observed at $9.6 \mathrm{mg} \mathrm{L}^{-1}$ of CYN after 7 days of exposure (Fig. 2), but it was only 0.86 -fold higher than the value found for the control. The NOEC and LOEC values of 17.3 and $38.7 \mathrm{mg} \mathrm{L}^{-1}$ were obtained for CYN on the 4th day

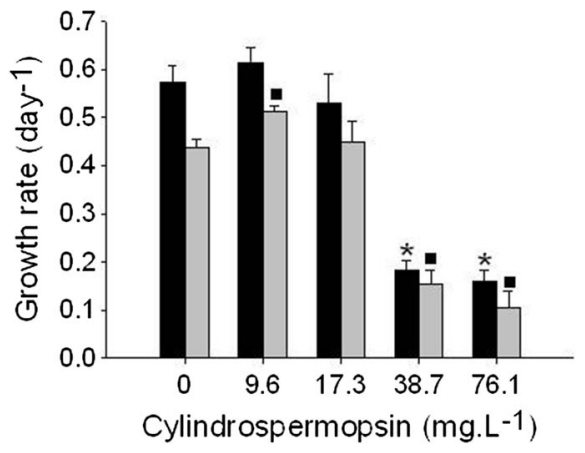

Asterisks and filled squares denotes data significantly different from control at the fourth and seventh day of exposure (Dunnett's method, $P<0.05)$

of exposure, respectively. For the 7th day of exposure, the LOEC value for CYN was $9.6 \mathrm{mg} \mathrm{L}^{-1}$.

The $\mathrm{EC}_{50}$ values obtained when $C$. vulgaris was exposed to $\mathrm{CYN}$ were $32.66 \mathrm{mg} \mathrm{L}^{-1}\left(\mathrm{SE}=3.91, R^{2}=0.90\right)$ and $33.24 \mathrm{mg} \mathrm{L}^{-1}\left(\mathrm{SE}=3.47, R^{2}=0.91\right)$ for the 4 th and 7 th days of exposure, respectively. As MC-LR did not describe a clear concentration-response relationship for the growth rate of $C$. vulgaris, it was impossible to calculate a valid $\mathrm{EC}_{50}$ value for this endpoint and further analysis in the MIXTOX tool had to be undertaken with fixed (extrapolated) $\mathrm{EC}_{50}$ and slope parameters.

\section{Mixture exposures}

The toxicity of the binary mixture of MC-LR and CYN on the 4 th and 7 th days of exposure was predicted by using the 
MIXTOX tool to fit the data set and generate the best description of the biological response of $C$. vulgaris to the combination of these cyanotoxins. For that, the CA model was the starting point used as the conceptual model for the fit of our data set that provides a conservative (protective) assessment of the mixture toxicity even though MC-LR and CYN have different MoA on the organism. All parameters and significance test results obtained from data fitted with the MIXTOX tool are presented in Table 2.

On the 4th day, the fit of the CA model to the binary mixture data of MC-LR and CYN exposure yielded a SS value of 0.24 , explaining $81 \%$ of our data $(p(\mathrm{~F})<0.001)$. After adding parameter $a$ to the CA model in order to describe synergism or antagonism, the SS value decreased slightly to $0.23\left(p\left(\chi^{2}\right)<0.001\right)$, explaining $83 \%$ of the data. Parameter $a$ had a value of -0.14 , which indicates synergism (Tables 1 and 2). Continuing in testing for deviations for DR dependency, no significant improvement was obtained on the data fit $\left(p\left(\chi^{2}\right)=0.17\right)$. When parameter $a$ and $b_{\mathrm{DL}}$ were used to extend the CA model and obtain a description for a DL pattern, no significant improvement was observed as well $\left(p\left(\chi^{2}\right)=0.22\right)$ (Table 2). Therefore, a synergism deviation from CA model was shown to be the best description for our data set $\left(\mathrm{SS}=0.23, R^{2}=0.83\right.$ and $p\left(\chi^{2}\right)<0.001$, Fig. 3).

For data on the 7th day of exposure, a similar pattern to the one obtained for the 4th day was achieved, starting with a significant fit to the CA model, explaining $83 \%$ of the data $(\mathrm{SS}=0.13, p(\mathrm{~F})<0.001)$. After adding parameter $a$ to the CA equation the SS value decreased slightly to 0.12 and the $R^{2}$ increased significantly to 0.85 and a synergistic pattern was suggested for the binary mixture of cyanotoxins $\left(a=-0.34, p\left(\chi^{2}\right)<0.001\right.$, Tables 1 and 2$)$. No significance decrease to the SS value was observed when adding parameter $a$ and $b_{\mathrm{DR}}$ to the DR deviation (SS $\left.=0.12, p\left(\chi^{2}\right)=0.08\right)$, nor adding parameter $a$ and $b_{\mathrm{DL}}$ to attain the DL deviation $\left(p\left(\chi^{2}\right)=0.37\right)$ (Table 2). Therefore, a synergism deviation from CA model, which was achieved by adding parameter $a$ to the equation, was also shown to be the best description for our data set (SS $=0.12, R^{2}=0.85$ and $p\left(\chi^{2}\right)<0.001$, Fig. 3 ).

In order to provide information on the magnitude of the synergistic effect on the growth rate of $C$. vulgaris on both days of exposure, the $\mathrm{EC}_{50}$ values for CYN in all MC-LR concentrations tested were estimated and the SRs calculated. The $\mathrm{EC}_{50}$ values and standard errors are provided in Table 3 with the corresponding SRs. From Table 3, it is possible to observe that MC-LR had a great effect on CYN toxicity with SRs of almost 2 at all exposure levels and periods.

\section{Discussion}

\section{Single exposures}

In this study, the log-phase growing freshwater algae $C$. vulgaris was exposed to a range of concentrations of MC-

Table 2 Summary of the analysis done for the effects on the growth rate of Chlorella vulgaris exposed for 4 and 7 days to the binary mixture of MC-LR and CYN

\begin{tabular}{|c|c|c|c|c|c|c|c|c|}
\hline \multirow[t]{3}{*}{ Day } & \multicolumn{8}{|c|}{ Concentration addition } \\
\hline & \multicolumn{2}{|l|}{ Reference } & \multicolumn{2}{|l|}{ S/A } & \multicolumn{2}{|l|}{ DR } & \multicolumn{2}{|l|}{ DL } \\
\hline & 4 & 7 & 4 & 7 & 4 & 7 & 4 & 7 \\
\hline $\operatorname{Max}$ & 0.63 & 0.48 & 0.63 & 0.48 & 0.62 & 0.48 & 0.62 & 0.48 \\
\hline$\beta_{M C-L R}{ }^{*}$ & 30 & 30 & 30 & 30 & 30 & 30 & 30 & 30 \\
\hline$\beta_{C Y N}$ & 2.27 & 2.53 & 2.29 & 2.60 & 2.37 & 2.70 & 2.10 & 2.59 \\
\hline $\mathrm{EC}_{50 \mathrm{MC}-\mathrm{LR}}{ }^{*}$ & 83 & 85 & 83 & 85 & 83 & 85 & 83 & 85 \\
\hline $\mathrm{EC}_{50 \mathrm{CYN}}$ & 28.75 & 30.72 & 29.06 & 31.45 & 30.14 & 32.31 & 29.62 & 31.69 \\
\hline$a$ & - & - & -0.14 & -0.34 & -1.85 & -1.89 & 2.69 & $9.52 \times 10^{-04}$ \\
\hline$b_{D R / D L}$ & - & - & - & - & 5.28 & 4.66 & 1.43 & -612.95 \\
\hline SS & 0.24 & 0.13 & 0.23 & 0.12 & 0.23 & 0.12 & 0.23 & 0.13 \\
\hline$R^{2}$ & 0.81 & 0.83 & 0.83 & 0.85 & 0.82 & 0.84 & 0.81 & 0.83 \\
\hline$p(\mathrm{~F}) / p\left(\chi^{2}\right)$ & $4.99 \times 10^{-35}$ & $4.83 \times 10^{-37}$ & $8.89 \times 10^{-03}$ & $9.31 \times 10^{-03}$ & 0.17 & 0.08 & 0.22 & 0.37 \\
\hline
\end{tabular}

$F$ test was used for reference model fit and $\chi^{2}$ test for improvement in fit and the quality of the model fits obtained $(\alpha=0.05)$. Fixed $\mathrm{EC}_{50}$ and $\beta$ parameters are indicated in italics

$S / A$ synergism/antagonism, $D R$ dose ratio deviation and $D L$ dose level deviation from the reference model, Max maximum response value obtained for the given endpoint, $\beta$ slope of the individual dose-response curve, $E C_{50}$ median effect concentration value, $a$ and $b_{D R / D L}$ parameters of the deviation functions, $S S$ sum of squared residuals, $R^{2}$ coefficient of determination, $\chi^{2}$ Chi squared test and $p\left(\chi^{2}\right)$ outcome of the likelihood ratio test (significance level $p<0.05$ )

* These values were overestimated, to allow prediction 
Fig. 3 Concentration-response relationship for the binary mixture of microcystin-LR and cylindrospermopsin showing a synergist pattern from the CA model for the growth rate of $C$. vulgaris on the fourth and seventh day of exposure (2D isobolic surface).

Concentrations of cyanotoxins reported as effective values
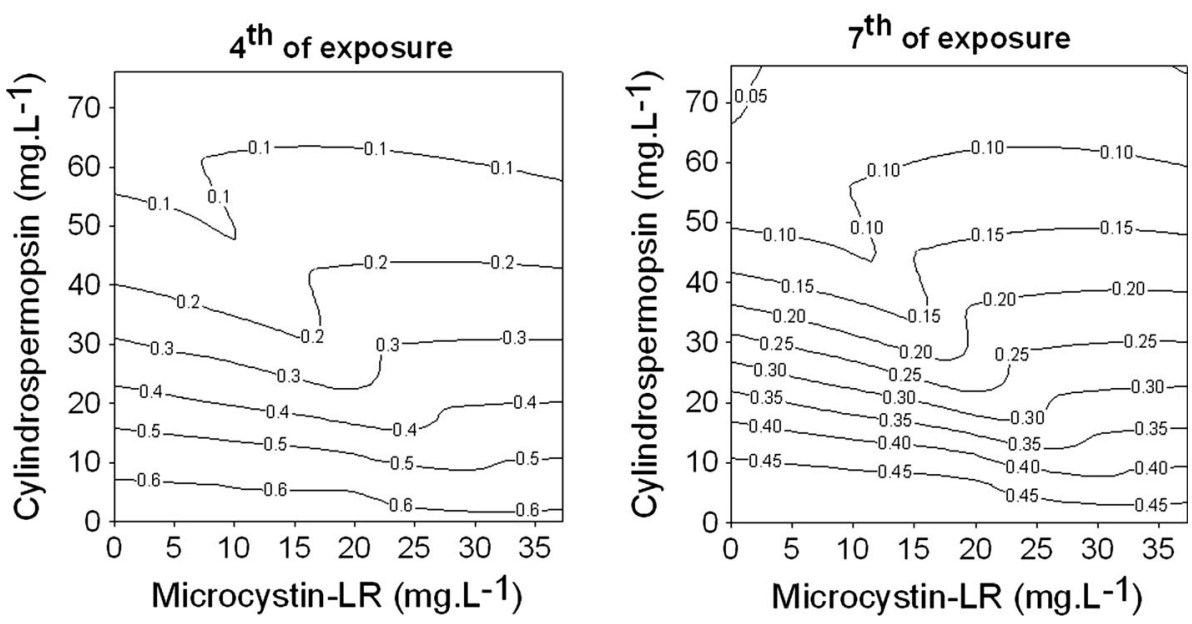

Table $3 \mathrm{EC}_{50}$ values for cylindrospermopsin exposure (with the standard errors, in $\mathrm{mg} \mathrm{L}^{-1}$ ) and synergistic ratios (SRs) estimated and calculated, respectively, when co-occurring with each concentration of microcystin-LR in the mixture experiments

\begin{tabular}{|c|c|c|c|c|c|c|c|}
\hline \multirow[t]{2}{*}{ Exposure time (days) } & & \multicolumn{6}{|c|}{ Microcystin-LR $\left(\mathrm{mg} \mathrm{L}^{-1}\right)$} \\
\hline & & 0 & 0.4 & 2.3 & 5.1 & 8.7 & 19.7 \\
\hline \multirow[t]{2}{*}{4} & $\mathrm{EC}_{50}( \pm \mathrm{SE})$ & $32.66( \pm 3.91)$ & $19.64( \pm 5.41)$ & 17.53 (n.d.) & 17.22 (n.d.) & 17.26 (n.d.) & $18.27( \pm 0.99)$ \\
\hline & $\mathrm{SR}^{\mathrm{a}}$ & - & 1.66 & 1.86 & 1.90 & 1.89 & 1.87 \\
\hline \multirow[t]{2}{*}{7} & $\mathrm{EC}_{50}( \pm \mathrm{SE})$ & $33.24( \pm 3.47)$ & 17.40 (n.d.) & 17.38 (n.d.) & $17.08( \pm 0.15)$ & $17.28( \pm 0.28)$ & $16.94( \pm 0.13)$ \\
\hline & $\mathrm{SR}^{\mathrm{a}}$ & - & 1.91 & 1.91 & 1.95 & 1.92 & 1.96 \\
\hline
\end{tabular}

$S E$ standard error, n.d. not determined

${ }^{\mathrm{a}} \mathrm{SR}=\mathrm{EC}_{50} \mathrm{CYN}$ without $\mathrm{MC}-\mathrm{LR} / \mathrm{EC}_{50 \mathrm{CYN}}$ and MC-LR treatments

LR and CYN that are not ecologically relevant for 7 days aiming at estimating the $\mathrm{EC}_{50}$ values for each of the cyanotoxins and then predict their combined toxicity using the conceptual model CA in the MIXTOX tool.

Our experiments demonstrated that CYN at higher concentrations than $38.7 \mathrm{mg} \mathrm{L}^{-1}$ could strongly affect the growth of $C$. vulgaris, inhibiting their growth rates by a factor higher or similar to three after 4 and 7 days of exposure. In a previous work, CYN slightly inhibited $C$. vulgaris growth rates $(<10 \%$ of inhibition) after 4 days of exposure at concentrations of 8.5 and $16.7 \mathrm{mg} \mathrm{L}^{-1}$, but no growth rate inhibition was observed on the 7 th day of exposure (Pinheiro et al. 2013). In the present study concentrations corresponding to 9.6 and $17.3 \mathrm{mg} \mathrm{L}^{-1}$ were found to be either completely ineffective or causing a weak growth stimulation (0.86-fold higher than control) in $C$. vulgaris during the exposure period. Moreover, MC-LR at concentrations higher than $6.5 \mathrm{mg} \mathrm{L}^{-1}$ was observed to stimulate the growth rates of $C$. vulgaris after 7 days of exposure. In previous studies, $C$. vulgaris growth rates were also found to be increased after the same exposure time, but only at $37.3 \mathrm{mg} \mathrm{L}^{-1}$ of MC-LR (Pinheiro et al. 2013). Similarly to our results, a few studies have reported significant stimulations on microalgae growth when exposed to MC concentrations lower or similar to $4 \mathrm{mg} \mathrm{L}^{-1}$. Ou et al. (2005) showed that the growth of the grazing chrysophyte Posterioochromonas sp. increased remarkably with the presence of MC-LR and MC-RR at concentrations between 0.1 and $4 \mathrm{mg} \mathrm{L}^{-1}$ within 17 days of exposure. Sedmak and Kosi (1998) observed an early growth stimulation of the green alga Coelastrum microporum when exposed to 0.1 and $0.5 \mathrm{mg} \mathrm{L}^{-1}$ of MC-RR in the first 10 days and a subsequent growth inhibition in the last 4 days. In a similar experiment with MC-RR and a different exposure time (16 days), the same authors also observed an increase on the growth of the green algae Monoraphidium contortum at $0.104 \mathrm{mg} \mathrm{L}^{-1}$ (Sedmak and Kosi 1998). In addition, a slight difference between the growth rates assessed on 4th and 7th days of exposure were noticed which, in the case of CYN, tend to disappear with increasing concentrations. Since no cyanotoxin degradation was observed and $C$. vulgaris was in log-phase at the end of 7 days, the expressive decreasing of growth rates between the 2 days may possibly be a result of nutrient depletion.

Previous works have shown that pure MCs may have detrimental effects on the microalgae growth at 
concentrations as high as those used in the present work. For example, Babica et al. (2007) demonstrated that the growth of five planktonic microalgae representatives of Chlorophyta (Chlamydomonas reinhardtii, Chlorella kesslerii, Pediastrum duplex, Raphidocelis subcapitata and Scenedesmus quadricauda) was strongly inhibited at $25 \mathrm{mg} \mathrm{L}^{-1}$ of MC-RR after 11 days of exposure. For the same concentration and exposure time, MC-LR induced similar growth inhibition only for $R$. subcapitata and $S$. quadricauda. $R$. subcapitata showed to be the most sensitive microalgae, being highly affected by both MC variants at even low concentrations ( 1 and $5 \mathrm{mg} \mathrm{L}^{-1}$ ). On the other hand, MC-LR (up to $25 \mathrm{mg} \mathrm{L}^{-1}$ and 11 days of exposure) had actually none or very weak effects on the growth of $C$. reinhardtii, C. kesslerii and P. duplex (Babica et al. 2007). This seems to be in very agreement with the results of our study, where no inhibition of $C$. vulgaris growth was observed in MC-LR exposure. It is possible that green algae species display differential susceptibilities to MCs. Moreover, microalgae responses to MCs seem to be also influenced by physic-chemical and environment factors. Some of these features were reported by Sedmak and Kosi (1998) who found that MC-RR at 0.104 and $0.519 \mathrm{mg} \mathrm{L}^{-1}$ inhibited $C$. microporum growth, but induced the growth of $M$. contortum and S. quadricauda under low light conditions. This highlights also the fact that under non controlled conditions, unlike those from toxicity tests, MC deleterious effects can be depicted at lower concentrations.

A clear concentration-response relationship for $C$. vulgaris growth rate was obtained for CYN in the single exposure experiment, with $\mathrm{EC}_{50}$ values of 32.66 and $33.24 \mathrm{mg} \mathrm{L}^{-1}$ for the 4th and 7 th days of exposure, respectively. These results are in agreement with what has been reported by Kinnear (2010) who claimed that exposure concentrations of pure CYN below $100 \mu \mathrm{g} \mathrm{L}^{-1}$ appear to have no significant harmful effects on a wide range of species (e.g. floating macrophytes and green algae), leading to the hypothesis that green algae have developed appropriate protective mechanisms to tolerate CYN. The concentrations required to exhibit $50 \%$ effects in this study are non-environmentally realistic because they are 2-400fold higher than those usually found in ecosystems. In Europe, concentrations of dissolved CYN associated with cyanobacterial blooms range from 0.8 to $18.4 \mu \mathrm{g} \mathrm{L}^{-1}$ (Bogialli et al. 2006; Gallo et al. 2009; Messineo et al. 2010; Quesada et al. 2006; Rücker et al. 2007). However, toxicity at low concentrations of CYN may not be excluded in even longer-term exposures. Unlike MCs, dissolved CYN tends to accumulate in the aquatic systems because of elevated extracellular release by $\mathrm{CYN}$-producing cyanobacteria (Preußel et al. 2009) and, considering its limited photodegradation (Wörmer et al. 2010) and biodegradation (Wormer et al. 2008), may impair the aquatic organisms.

On the other hand, MC-LR did not induce a concentration-response relationship for $C$. vulgaris growth rates. For this reason, it was impossible to calculate $\mathrm{EC}_{50}$ values for this endpoint in the single exposure experiment. Concentrations of dissolved MCs in natural waters are generally reported below $10 \mu \mathrm{g} \mathrm{L}^{-1}$ because they are mainly retained within healthy cyanobacterial cells (Babica et al. 2006, 2007; Wiegand and Pflugmacher 2005). However, concentrations of MCs above $10 \mu \mathrm{g} \mathrm{L}^{-1}$ in the environment can occur immediately after the collapse of a cyanobacterial bloom or the application of algicides. Jones and Orr (1994) measured 1.3-1.8 $\mathrm{mg} \mathrm{L}^{-1} \mathrm{MCs}$ following algicide treatment of a $M$. aeruginosa bloom in a recreational lake. Furthermore, in a few cases, accumulation of cyanobacterial cell in surface scum may raise MC concentrations to levels higher than $1.8 \mathrm{mg} \mathrm{L}^{-1}$. In addition, concentrations of total MCs up to $8.4-25 \mathrm{mg} \mathrm{L}^{-1}$ have been reported in natural bloom samples (Fastner et al. 1999; Kemp and John 2006; Máthé et al. 2007; Nagata et al. 1997). Although high MC-LR concentrations were not harmful to $C$. vulgaris, effects on aquatic organisms, especially microalgae, at low concentrations of MC-LR in longer-term exposures cannot be disregarded. Some studies have reported toxic effects of MC-LR on microalgae at concentrations below $1.1 \mathrm{mg} \mathrm{L}^{-1}$ in a 12- and 14-day exposure period (B-Béres et al. 2012; Kearns and Hunter 2000, 2001; Sedmak and Eleršek 2006), suggesting that for longer periods of exposure, low concentrations may be harmful. High concentrations of MC-LR together with longer exposure periods may also cause severe impact on aquatic ecosystems. Evidence supporting this is shown in the work of Sedmak and Kosi (1998). These authors studied the relationship between the species diversity and the development of toxic cyanobacterial blooms and MC content in natural water bodies in which it was found a negative correlation between high cyanobacterial cell densities and high MC values $\left(>10 \mu \mathrm{g} \mathrm{L}^{-1}\right)$ and the number of phytoplankton species present.

\section{Mixture exposure}

The CA model was the conceptual model chosen to fit the data set from MC-LR and CYN binary mixture even though both cyanotoxins have different MoA. This model is considered more conservative than the independent action model, and it also allows to predict toxicity of mixtures where one (or both) of the stressors do not exert a complete concentration-response curve or a significant effect (Backhaus et al. 2004; Boedeker et al. 1993). At the molecular level, MC-LR mainly inhibits protein phosphatases 1 and $2 \mathrm{~A}$ in mammals and higher plants 
(Mackintosh et al. 1990), which cause intracellular problems with cell growth, differentiation and osmoregulation (Gulledge et al. 2002; Monserrat et al. 2003; Runnegar et al. 1995a). MC-LR can also cause oxidative stress in aquatic animals, plants and algae, leading to an increase in lipid peroxidation, DNA and mitochondrial damage and alteration of the antioxidant defense system (Amado and Monserrat 2010; Bártová et al. 2011; Mohamed 2008; Pflugmacher 2004). CYN, on the other hand, do not still have its molecular mechanism of toxicity established; however CYN is known to inhibit glutathione and protein synthesis in mammals and plants (Froscio et al. 2001, 2008; Metcalf et al. 2004; Runnegar et al. 1995b; Terao et al. 1994) interfering with several metabolic pathways.

According to the MIXTOX analysis, synergism was the deviation function from the CA model obtained for MC-LR and CYN mixture in both exposure periods. Synergistic deviations from conceptual models have been found in previous studies with aquatic organism (e.g. invertebrates, algae and macrophytes) and other chemicals (e.g. metals and pesticides) (Ferreira et al. 2008; Loureiro et al. 2010; Munkegaard et al. 2008), showing that there may be an interaction between chemicals rather than an additive or independent response. Toxicity of the MC-LR and CYN mixture was indeed higher than that predicted by the CA model, demonstrating that the conceptual model in this case was inaccurate in predicting the combined responses. Therefore, the CA model underestimated the mixture toxicity and a synergistic pattern was established for $C$. vulgaris growth responses. This result does not corroborate our second hypothesis that MC-LR and CYN could have an additive response on the microalgae growth. As far as we know, the present study is the first one to investigate the response patterns of green algae, the important representatives of lower trophic levels of aquatic food chain, to a mixture with pure cyanotoxins. Recently, some studies have been reported synergistic effect on the oxidative stress responses of higher plants exposed to a mixture containing purified cyanotoxins or cyanobacterial cell extracts (Freitas et al. 2015; Prieto et al. 2011). Freitas et al. (2015) showed that a mixture of pure MC-LR and CYN $\left(1-100 \mu \mathrm{g} \mathrm{L}^{-1}\right)$ promoted a significant increase of glutathione S-transferase (GST) activity in the roots of the lettuce plant Lactuta sativa after 5 days of exposure when compared to MC-LR and $\mathrm{CYN}$ alone, suggesting a synergistic effect between both cyanotoxins. Similarly, in a 48 h-experiment, Prieto et al. (2011) reported that the exposure of the rice plant Oryza sativa to a mixture of $A$. ovalisporum and $M$. aeruginosa cell extracts containing CYN $\left(0.13 \mu \mathrm{g} \mathrm{L}^{-1}\right)$ and MC-LR $\left(50 \mu \mathrm{g} \mathrm{L}^{-1}\right)$, respectively, resulted in a significant increase in GST activity in the roots and leaves compared to that obtained with the individual cell extracts, also suggesting a synergistic effect between both extracts/cyanotoxins. It should be stressed that both cyanobacterial extracts are complex mixtures of cyanobacterial metabolites (including cyanotoxins) and potential interactions among them cannot be neglected. As an example, Nováková et al. (2012) studied the combined effects of crude extracts from two non-producing cyanobacteria, Aphanizomenon gracile and Cylindrospermosis raciborskii, on gap junctional intercellular communication (GJIC) and showed that both extracts (without cyanotoxins) when combined caused an additive response on GJIC, suggesting that unknown metabolites are responsible for the inhibitory activity of GJIC. Therefore, the toxicity of mixtures of cyanobacterial extracts containing cyanotoxins should be analyzed with more reflection and prudency.

The current study used high concentrations of MC-LR (0.4-19.7 $\left.\mathrm{mg} \mathrm{L}^{-1}\right)$ and CYN (0.4-16.7 $\left.\mathrm{mg} \mathrm{L}^{-1}\right)$ in order to assess their combined effects on the growth responses of C. vulgaris. Although MC-LR has not caused any inhibitory effect on the $C$. vulgaris growth at high concentrations in the single exposure experiment in any exposure time, its presence at levels lower than $20 \mathrm{mg} \mathrm{L}^{-1}$ in a mixture with CYN significantly increased the toxicity of CYN. This indicates a synergistic interaction between the tested cyanotoxins. For this reason and in order to estimate the magnitude of the synergistic effect on the growth rates as a result of the MC-LR mixture with CYN, SRs were calculated for each MC-LR concentration tested. MC-LR at 0.4-19.7 $\mathrm{mg} \mathrm{L}^{-1}$ increased the toxicity of CYN by about a factor of 2 (Table 3). This is an important finding if considering that levels of 2-10 times this amount of MC-LR did not cause toxicity by itself. The most likely explanation for this increased toxicity is that the simultaneous exposure to MC-LR and CYN may lead to a reduction of reduced glutathione (GSH) pool in cells caused by MC-LR detoxification (via GST) (Pflugmacher et al. 1998), which may have resulted in a higher requirement of GSH synthesis. Because CYN is an inhibitor of GSH synthesis, it may impair the capacity of green algae to detoxify MC-LR and increase its residence time within cells, promoting thereby a much higher toxicity. Therefore understanding the potential interaction between the MoA of MC-LR and CYN could be further studied at a lower organizational level (e.g. cellular level). Best et al. (2002), who investigated the combined effect of MC-LR and lipopolysaccharides (LPS) on the GST activity of zebra fish Danio rerio, also reported that LPS $\left(0.5 \mu \mathrm{g} \mathrm{L}^{-1}\right)$ may exert a synergistic effect on MC-LR-induced toxicity $\left(0.5 \mu \mathrm{g} \mathrm{L}^{-1}\right)$ possibly due to the decrease of the GST activity caused by LPS and reduction of MC-LR detoxification. In contrast to the previous study, Lindsay et al. (2006) showed a non-fully understood antagonistic effect between MC-LR or CYN and LPS in invertebrates (namely, Artemia salina, Daphnia 
magna and Daphnia galeata); pre-exposure with a sublethal level of LPS $\left(2 \mu \mathrm{g} \mathrm{L}^{-1}\right)$ protect the invertebrates against the toxicity of MC-LR and CYN $\left(1 \mu \mathrm{g} \mathrm{L}^{-1}\right.$ $20 \mathrm{mg} \mathrm{L}^{-1}$ ). This protective effect was also observed for the co-exposure of LPS and MC-LR, but was less pronounced than that conferred by pre-exposure with LPS. On the other hand, Pires et al. (2011) did not found clear evidences for synergistic effects of MCs and LPS, but the interaction between Microcystis strain type (non-producing and MC-producing), concentration of MC-producing cells and LPS (absence or presence) was significant, indicating mixture composition dependent effects, i.e., dose-ratio dependency. The variety of responses produced by cyanotoxin mixtures indicates that the observed toxic effects are likely dependent on the species, mixture composition, exposure type and levels of cyanotoxins used.

The lowest MC-LR concentration tested $\left(0.4 \mathrm{mg} \mathrm{L}^{-1}\right)$ had SR values around 2 in both exposure times, meaning that the toxicity is potentiated. Despite these concentrations are not considered environmentally relevant (only relevant in bloom collapse scenarios), the ecological risk assessment should take this potentiating effect into account when planning to evaluate the increased risk of this kind of mixture to the environment, since even low cyanotoxin concentrations may sum up (or more than the sum) toxic effects when occurring in mixtures. The impact of such potentiating effect to the environment and in particular to microalgae community may be further increased if we consider that MC-LR and CYN are relatively stable compounds (Chiswell et al. 1999; Tsuji et al. 1994; Wormer et al. 2008) and may persist in the water after cyanobacterial senescence and/or cell lyses (Eaglesham et al. 1999). Given predictions that cyanobacterial blooms will increase in frequency and magnitude in the future, we might anticipate that synergistic effects on growth responses of microalgae, which will influence exponential population growth, may have pronounced effects on populations and communities of zooplankton.

\section{Conclusions}

In the present study, $C$. vulgaris was chosen as a test species to discuss the toxic effects of individual and mixture exposure of pure MC-LR and CYN. Our results showed that the interaction between MC-LR and CYN was synergistic and MC-LR increased the CYN toxicity on the C. vulgaris growth. Although the synergistic interaction between MC-LR and CYN occurred at high concentrations, further investigation is required to assess environmentally relevant combinations, as potential synergistic effects at low concentrations cannot be excluded. To the best of our knowledge, this is the first study concerning combined toxicity of MC-LR and CYN as pure cyanotoxins in microalgae. Considering the predicted expansion of cyanobacterial blooms on a global scale, this report is also an important contribution to our understanding of an increasing potential environmental risk between MC-LR and CYN and how both cyanotoxins interact with each other in microalgae. Moreover, our results demonstrated that high concentration of CYN applied as single cyanotoxin caused impairments on growth rates of $C$. vulgaris while MC-LR can lead generally to an increase of the growth rates.

Given the importance of microalgae such as $C$. vulgaris in the food webs and the growing concerns regarding cyanobacterial blooms, we suggest that there is a need to carefully assess the mechanism behind this synergistic effect.

Acknowledgments This work was supported by the Portuguese Science Foundation (FCT) through CESAM: UID/AMB/50017/2013.

\section{Compliance with ethical standards}

Conflict of interest The authors declare that they have no conflict of interest.

\section{References}

Amado LL, Monserrat JM (2010) Oxidative stress generation by microcystins in aquatic animals: why and how. Environ Int 36:226-235. doi:10.1016/j.envint.2009.10.010

Babica P, Bláha L, Maršálek B (2006) Exploring the natural role of microcystins-a review of effects on photoautotrophic organisms. J Phycol 42:9-20. doi:10.1111/j.1529-8817.2006.00176.x

Babica P, Hilscherová K, Bártová K, Bláha L, Maršálek B (2007) Effects of dissolved microcystins on growth of planktonic photoautotrophs. Phycologia 46:137-142. doi:10.2216/06-24.1

Backhaus T, Arrhenius A, Blanck H (2004) Toxicity of a mixture of dissimilarly acting substances to natural algal communities: predictive power and limitations of independent action and concentration addition. Environ Sci Technol 38:6363-6370. doi:10.1021/es0497678

Banker R, Teltsch B, Sukenik A, Carmeli S (2000) 7-epicylindrospermopsin, a toxic minor metabolite of the cyanobacterium Aphanizomenon ovalisporum from Lake Kinneret, Israel. J Nat Prod 63:387-389

Bártová K, Hilscherová K, Babica P, Maršálek B, Bláha L (2011) Effects of microcystin and complex cyanobacterial samples on the growth and oxidative stress parameters in green alga Pseudokirchneriella subcapitata and comparison with the model oxidative stressor-herbicide paraquat. Environ Toxicol 26:641-648. doi:10.1002/tox.20601

B-Béres V et al (2012) The effects of Microcystis aeruginosa (cyanobacterium) on Cryptomonas ovata (Cryptophyta) in laboratory cultures: why these organisms do not coexist in steady-state assemblages? Hydrobiologia 691:97-107. doi:10. 1007/s10750-012-1061-9

Best JH, Pflugmacher S, Wiegand C, Eddy FB, Metcalf JS, Codd GA (2002) Effects of enteric bacterial and cyanobacterial lipopolysaccharides, and of microcystin-LR, on glutathione 
S-transferase activities in zebra fish (Danio rerio). Aquat Toxicol 60:223-231

Beyer D et al (2009) Cylindrospermopsin induces alterations of root histology and microtubule organization in common reed (Phragmites australis) plantlets cultured in vitro. Toxicon 54:440-449. doi:10.1016/j.toxicon.2009.05.008

Bláha L, Babica P, Maršálek B (2009) Toxins produced in cyanobacterial water blooms-toxicity and risks. Interdiscip Toxicol 2:36-41

Bláhová L, Oravec M, Maršálek B, Šejnohová L, Šimek Z, Bláha L (2009) The first occurrence of the cyanobacterial alkaloid toxin cylindrospermopsin in the Czech Republic as determined by immunochemical and LC/MS methods. Toxicon 53:519-524. doi:10.1016/j.toxicon.2009.01.014

Boedeker W, Drescher K, Altenburger R, Faust M, Grimme LH (1993) Combined effects of toxicants: the need and soundness of assessment approaches in ecotoxicology. Sci Total Environ 134(Supplement 2):931-939

Bogialli S, Bruno M, Curini R, Di Corcia A, Fanali C, Laganà A (2006) Monitoring algal toxins in lake water by liquid chromatography tandem mass spectrometry. Environ Sci Technol 40:2917-2923. doi:10.1021/es052546x

Brient L, Lengronne M, Bormans M, Fastner J (2009) First occurrence of cylindrospermopsin in freshwater in France. Environ Toxicol 24:415-420. doi:10.1002/tox.20439

Chiswell RK, Shaw GR, Eaglesham G, Smith MJ, Norris RL, Seawright AA, Moore MR (1999) Stability of cylindrospermopsin, the toxin from the cyanobacterium, Cylindrospermopsis raciborskii: effect of $\mathrm{pH}$, temperature, and sunlight on decomposition. Environ Toxicol 14:155-161

Codd GA, Bell SG, Kaya K, Ward CJ, Beattie KA, Metcalf JS (1999) Cyanobacterial toxins, exposure routes and human health. Eur J Phycol 34:405-415. doi:10.1017/s0967026299002255

Dittmann E, Wiegand C (2006) Cyanobacterial toxins-occurrence, biosynthesis and impact on human affairs. Mol Nutr Food Res 50:7-17. doi:10.1002/mnfr.200500162

Eaglesham GK et al (1999) Use of HPLC-MS/MS to monitor cylindrospermopsin, a blue-green algal toxin, for public health purposes. Environ Toxicol 14:151-154. doi:10.1002/(sici)15227278(199902)14:1<151:aid-tox19>3.0.co;2-d

European Food Safety Authority (2015) Harmonisation of human and ecological risk assessment of combined exposure to multiple chemicals

Falconer IR (1999) An overview of problems caused by toxic bluegreen algae (cyanobacteria) in drinking and recreational water. Environ Toxicol 14:5-12

Falconer IR, Humpage AR (2005) Cyanobacterial toxins of drinking water supplies: cylindrospermopsins and microcystins. CRC Press, Boca Raton

Falconer IR, Humpage AR (2006) Cyanobacterial (blue-green algal) toxins in water supplies: cylindrospermopsins. Environ Toxicol 21:299-304. doi:10.1002/tox.20194

Fastner J, Neumann U, Wirsing B, Weckesser J, Wiedner C, Nixdorf B, Chorus I (1999) Microcystins (hepatotoxic heptapeptides) in German fresh water bodies. Environ Toxicol 14:13-22. doi:10. 1002/(sici)1522-7278(199902)14:1<13:aid-tox4>3.0.co;2-d

Fastner J et al (2007) Occurrence of the cyanobacterial toxin cylindrospermopsin in northeast Germany. Environ Toxicol 22:26-32. doi:10.1002/tox.20230

Ferreira ALG, Loureiro S, Soares A (2008) Toxicity prediction of binary combinations of cadmium, carbendazim and low dissolved oxygen on Daphnia magna. Aquat Toxicol 89:28-39. doi:10.1016/j.aquatox.2008.05.012

Freitas M, Azevedo J, Pinto E, Neves J, Campos A, Vasconcelos V (2015) Effects of microcystin-LR, cylindrospermopsin and a microcystinLR/cylindrospermopsin mixture on growth, oxidative stress and mineral content in lettuce plants (Lactuca sativa L.). Ecotoxicol Environ Safe 116:59-67. doi:10.1016/j.ecoenv.2015.02.002

Froscio SM, Humpage AR, Burcham PC, Falconer IR (2001) Cellfree protein synthesis inhibition assay for the cyanobacterial toxin cylindrospermopsin. Environ Toxicol 16:408-412

Froscio SM, Humpage AR, Wickramasinghe W, Shaw G, Falconer IR (2008) Interaction of the cyanobacterial toxin cylindrospermopsin with the eukaryotic protein synthesis system. Toxicon 51:191-198. doi:10.1016/j.toxicon.2007.09.001

Gallo P, Fabbrocino S, Cerulo MG, Ferranti P, Bruno M, Serpe L (2009) Determination of cylindrospermopsin in freshwaters and fish tissue by liquid chromatography coupled to electrospray ion trap mass spectrometry. Rapid Commun Mass Spectrom 23:3279-3284. doi:10.1002/rcm.4243

Gantar M, Berry JP, Thomas S, Wang ML, Perez R, Rein KS (2008) Allelopathic activity among Cyanobacteria and microalgae isolated from Florida freshwater habitats. FEMS Microbiol Ecol 64:55-64. doi:10.1111/j.1574-6941.2008.00439.x

Gulledge BM, Aggen JB, Huang HB, Nairn AC, Chamberlin AR (2002) The microcystins and nodularins: cyclic polypeptide inhibitors of PP1 and PP2A. Curr Med Chem 9:1991-2003

Humpage AR, Fontaine F, Froscio S, Burcham P, Falconer IR (2005) Cylindrospermopsin genotoxicity and cytotoxicity: role of cytochrome P-450 and oxidative stress. J Toxicol Environ Health A 68:739-753. doi:10.1080/15287390590925465

Jones GJ, Orr PT (1994) Release and degradation of microcystin following algicide treatment of a Microcystis aeruginosa bloom in a recreational lake, as determined by HPLC and protein phosphatase inhibition assay. Water Res 28:871-876

Jonker MJ, Svendsen C, Bedaux JJM, Bongers M, Kammenga JE (2005) Significance testing of synergistic/antagonistic, dose level-dependent, or dose ratio-dependent effects in mixture dose-response analysis. Environ Toxicol Chem 24:2701-2713

Kearns KD, Hunter MD (2000) Green algal extracellular products regulate antialgal toxin production in a cyanobacterium. Environ Microbiol 2:291-297

Kearns KD, Hunter MD (2001) Toxin-producing Anabaena flosaquae induces settling of Chlamydomonas reinhardtii, a competing motile alga. Microb Ecol 42:80-86

Kemp A, John J (2006) Microcystins associated with Microcystis dominated blooms in the southwest wetlands, Western Australia. Environ Toxicol 21:125-130. doi:10.1002/tox.20164

Kinnear S (2010) Cylindrospermopsin: a decade of progress on bioaccumulation research. Mar Drugs 8:542-564. doi:10.3390/ md8030542

Kokociński M, Dziga D, Spoof L, Stefaniak K, Jurczak T, Mankiewicz-Boczek J, Meriluoto J (2009) First report of the cyanobacterial toxin cylindrospermopsin in the shallow, eutrophic lakes of western Poland. Chemosphere 74:669-675. doi:10.1016/j.chemosphere.2008.10.027

Kotai J (1972) Instructions for the preparation of modified nutrient solution Z8 for algae. Norwegian Institute for Water Research, Blindern

Lahti K, Rapala J, Färdig M, Niemelä M, Sivonen K (1997) Persistence of cyanobacterial hepatotoxin, microcystin-LR in particulate material and dissolved in lake water. Water Res 31:1005-1012

Lindsay J, Metcalf JS, Codd GA (2006) Protection against the toxicity of microcystin-LR and cylindrospermopsin in Artemia salina and Daphnia spp. by pre-treatment with cyanobacterial lipopolysaccharide (LPS). Toxicon 48:995-1001. doi:10.1016/j. toxicon.2006.07.036

Loureiro S, Svendsen C, Ferreira ALG, Pinheiro C, Ribeiro F, Soares A (2010) Toxicity of three binary mixtures to Daphnia magna: comparing chemical modes of action and deviations from conceptual models. Environ Toxicol Chem 29:1716-1726. doi:10.1002/etc. 198 
Mackintosh C, Beattie KA, Klumpp S, Cohen P, Codd GA (1990) Cyanobacterial microcystin-LR is a potent and specific inhibitor of protein phosphatases 1 and $2 \mathrm{~A}$ from both mammals and higher plants. FEBS Lett 264:187-192

Máthé C et al (2007) Microcystin-LR, a cyanobacterial toxin, induces growth inhibition and histological alterations in common reed (Phragmites australis) plants regenerated from embryogenic calli. New Phytol 176:824-835. doi:10.1111/j.1469-8137.2007. 02230.x

Máthé C, M-Hamvas M, Vasas G (2013) Microcystin-LR and cylindrospermopsin Induced alterations in chromatin organization of plant cells. Mar Drugs 11:3689-3717. doi:10.3390/ md11103689

Messineo V, Melchiorre S, Di Corcia A, Gallo P, Bruno M (2010) Seasonal succession of Cylindrospermopsis raciborskii and Aphanizomenon ovalisporum blooms with cylindrospermopsin occurrence in the volcanic lake Albano, Central Italy. Environ Toxicol 25:18-27. doi:10.1002/tox.20469

Metcalf JS, Barakate A, Codd GA (2004) Inhibition of plant protein synthesis by the cyanobacterial hepatotoxin, cylindrospermopsin. FEMS Microbiol Lett 235:125-129. doi:10.1016/j. femsle.2004.04.025

Mohamed ZA (2008) Polysaccharides as a protective response against microcystin-induced oxidative stress in Chlorella vulgaris and Scenedesmus quadricauda and their possible significance in the aquatic ecosystem. Ecotoxicology 17:504-516. doi:10.1007/ s10646-008-0204-2

Monserrat JM, Pinho GLL, Yunes JS (2003) Toxicological effects of hepatotoxins (microcystins) on aquatic organisms. Comments on Toxicology 9:89-101

Munkegaard M, Abbaspoor M, Cedergreen N (2008) Organophosphorous insecticides as herbicide synergists on the green algae Pseudokirchneriella subcapitata and the aquatic plant Lemna minor. Ecotoxicology 17:29-35. doi:10.1007/s10646-007-0173$\mathrm{x}$

Nagata S, Tsutsumi T, Hasegawa A, Yoshida F, Ueno Y, Watanabe MF (1997) Enzyme immunoassay for direct determination of microcystins in environmental water. J AOAC Int 80:408-417

Neumann C, Bain P, Shaw G (2007) Studies of the comparative in vitro toxicology of the cyanobacterial metabolite deoxycylindrospermopsin. J Toxicol Environ Health A 70:1679-1686. doi:10.1080/15287390701434869

Norris RL et al (1999) Deoxycylindrospermopsin, an analog of cylindrospermopsin from Cylindrospermopsis raciborskii. Environ Toxicol 14:163-165

Norris RLG et al (2002) Hepatic xenobiotic metabolism of cylindrospermopsin in vivo in the mouse. Toxicon 40:471-476

Nováková K, Bláha L, Babica P (2012) Tumor promoting effects of cyanobacterial extracts are potentiated by anthropogenic contaminants-Evidence from in vitro study. Chemosphere $89: 30-37$

OECD (2006) OECD Guidelines for the testing of chemicals 201, freshwater alga and cyanobacteria, growth inhibition test. OECD, Paris

Oehrle SA, Southwell B, Westrick J (2010) Detection of various freshwater cyanobacterial toxins using ultra-performance liquid chromatography tandem mass spectrometry. Toxicon 55:965-972. doi:10.1016/j.toxicon.2009.10.001

Olmstead AW, LeBlanc GA (2005) Toxicity assessment of environmentally relevant pollutant mixtures using a heuristic model. Integr Environ Assess Manag 1:114-122. doi:10.1897/ieam_ 2004-005r.1

Ou DY, Song LR, Gan NQ, Chen W (2005) Effects of microcystins on and toxin degradation by Poterioochromonas sp. Environ Toxicol 20:373-380. doi:10.1002/tox.20114
Paerl HW, Huisman J (2008) Climate-blooms like it hot. Science 320:57-58. doi:10.1126/science. 1155398

Paerl HW, Huisman J (2009) Climate change: a catalyst for global expansion of harmful cyanobacterial blooms. Environ Microbiol Rep 1:27-37. doi:10.1111/j.1758-2229.2008.00004.x

Paerl HW, Paul VJ (2012) Climate change: links to global expansion of harmful cyanobacteria. Water Res 46:1349-1363. doi:10. 1016/j.watres.2011.08.002

Pereira S, Saker ML, Vale M, Vasconcelos VM (2009) Comparison of sensitivity of grasses (Lolium perenne L. and Festuca rubra L.) and lettuce (Lactuca sativa L.) exposed to water contaminated with microcystins. Bull Environ Contam Toxicol 83:81-84. doi:10.1007/s00128-009-9763-z

Pflugmacher S (2004) Promotion of oxidative stress in the aquatic macrophyte Ceratophyllum demersum during biotransformation of the cyanobacterial toxin microcystin-LR. Aquat Toxicol 70:169-178. doi:10.1016/j.aquatox.2004.06.010

Pflugmacher S, Wiegand C, Oberemm A, Beattie KA, Krause E, Codd GA, Steinberg CEW (1998) Identification of an enzymatically formed glutathione conjugate of the cyanobacterial hepatotoxin microcystin-LR: the first step of detoxication. Biochim Biophys Acta 1425:527-533

Pflugmacher S, Codd GA, Steinberg CEW (1999) Effects of the cyanobacterial toxin microcystin-LR on detoxication enzymes in aquatic plants. Environ Toxicol 14:111-115

Pinheiro C, Azevedo J, Campos A, Loureiro S, Vasconcelos V (2013) Absence of negative allelopathic effects of cylindrospermopsin and microcystin-LR on selected marine and freshwater phytoplankton species. Hydrobiologia 705:27-42. doi:10.1007/ s10750-012-1372-x

Pires LMD, Sarpe D, Brehm M, Ibelings BW (2011) Potential synergistic effects of microcystins and bacterial lipopolysaccharides on life history traits of Daphnia galeata raised on low and high food levels. Aquat toxicol 104:230-242

Preußel K, Wessel G, Fastner J, Chorus I (2009) Response of cylindrospermopsin production and release in Aphanizomenon flos-aquae (Cyanobacteria) to varying light and temperature conditions. Harmful Algae 8:645-650. doi:10.1016/j.hal.2008. 10.009

Prieto A, Campos A, Cameán A, Vasconcelos V (2011) Effects on growth and oxidative stress status of rice plants (Oryza sativa) exposed to two extracts of toxin-producing cyanobacteria (Aphanizomenon ovalisporum and Microcystis aeruginosa). Ecotoxicol Environ Saf 74:1973-1980. doi:10.1016/j.ecoenv. 2011.06.009

Quesada A, Moreno E, Carrasco D, Paniagua T, Wormer L, De Hoyos C, Sukenik A (2006) Toxicity of Aphanizomenon ovalisporum (Cyanobacteria) in a Spanish water reservoir. Eur J Phycol 41:39-45. doi:10.1080/09670260500480926

Rücker J, Stüken A, Nixdorf B, Fastner J, Chorus I, Wiedner C (2007) Concentrations of particulate and dissolved cylindrospermopsin in 21 Aphanizomenon-dominated temperate lakes. Toxicon 50:800-809. doi:10.1016/j.toxicon.2007.06.019

Runnegar M, Berndt N, Kong SM, Lee EYC, Zhang LF (1995a) In vivo and in vitro binding of microcystin to protein phosphatase 1 and 2A. Biochem Biophys Res Commun 216:162-169

Runnegar MT, Kong SM, Zhong YZ, Lu SC (1995b) Inhibition of reduced glutathione synthesis by cyanobacterial alkaloid cylindrospermopsin in cultured rat hepatocytes. Biochem Pharmacol 49:219-225

Sedmak B, Eleršek T (2006) Microcystins induce morphological and physiological changes in selected representative phytoplanktons. Microb Ecol 51:508-515. doi:10.1007/s00248-006-9045-9

Sedmak B, Kosi G (1998) The role of microcystins in heavy cyanobacterial bloom formation. J Plankton Res 20:691-708 
Spoof L et al (2006) First observation of cylindrospermopsin in Anabaena lapponica isolated from the boreal environment (Finland). Environ Toxicol 21:552-560. doi:10.1002/tox.20216

Terao K et al (1994) Electron microscopic studies on experimental poisoning in mice induced by cylindrospermopsin isolated from blue-green alga Umezakia natans. Toxicon 32:833-843

Tsuji K, Naito S, Kondo F, Ishikawa N, Watanabe MF, Suzuki M, Harada K (1994) Stability of microcystins from cyanobacteria: effect of light on decomposition and isomerization. Environ Sci Technol 28:173-177

van Apeldoorn ME, van Egmond HP, Speijers GJA, Bakker GJI (2007) Toxins of cyanobacteria. Mol Nutr Food Res 51:7-60. doi:10.1002/mnfr.200600185

Vasas G, Gáspár A, Páger C, Surányi G, Máthé C, Hamvas MM, Borbely G (2004) Analysis of cyanobacterial toxins (anatoxin-a, cylindrospermopsin, microcystin-LR) by capillary electrophoresis. Electrophoresis 25:108-115. doi:10.1002/elps.200305641

Wiegand C, Pflugmacher S (2005) Ecotoxicological effects of selected cyanobacterial secondary metabolites a short review. Toxicol Appl Pharmacol 203:201-218. doi:10.1016/j.taap.2004. 11.002

Wormer L, Cirés S, Carrasco D, Quesada A (2008) Cylindrospermopsin is not degraded by co-occurring natural bacterial communities during a 40-day study. Harmful Algae 7:206-213. doi:10.1016/j.ha1.2007.07.004

Wörmer L, Huerta-Fontela M, Cirés S, Carrasco D, Quesada A (2010) Natural photodegradation of the cyanobacterial toxins microcystin and cylindrospermopsin. Environ Sci Technol 44:3002-3007. doi:10.1021/es9036012

Zurawell RW, Chen HR, Burke JM, Prepas EE (2005) Hepatotoxic cyanobacteria: a review of the biological importance of microcystins in freshwater environments. J Toxicol Env Health B Crit Rev 8:1-37. doi:10.1080/10937400590889412 